\title{
The effect of genistein on some hormones and metabolic parameters in the immature, female rats ${ }^{*}$
}

\author{
L. Nogowski, E. Nowicka, T. Szkudelski ${ }^{1}$ and K. Szkudelska \\ The August Cieszkowski Agricultural University of Poznan', \\ Department of Animal Physiology and Biochemistry \\ 60-637 Wotyńska 35, Poznań, Poland
}

(Received 9 January 2007; revised version 13 March 2007; accepted 2 May 2007)

\begin{abstract}
The influence of isoflavone-genistein on some hormones and metabolic parameters in sexually immature, female rats was studied. Rats (34 days old) were divided into three groups: control (receiving no genistein), receiving 1 or $5 \mathrm{mg}$ of genistein $/ \mathrm{kg}$ body weight (BW). The tested compound was administered intragastrically, i.e. by using a cannula inserted via oesophagus into the stomach once a day for seven days. In genistein-treated rats body weight gains were unchanged in comparison to control animals. Genistein at a higher dose caused a significant $(\mathrm{P} \leq 0.01)$ decrease in blood insulin concentrations. Simultaneously, in animals treated with this phytoestrogen $(5 \mathrm{mg} / \mathrm{kg} \mathrm{BW})$ blood leptin was significantly reduced $(\mathrm{P} \leq 0.01)$. This latter effect was probably due to the direct inhibitory influence of genistein on leptin secretion from adipocytes. Thyrotropin, total and free triiodothyronine and thyroxine were not changed by the tested phytoestrogen. Several metabolic parameters determined in blood (glucose, triglycerides, free fatty acids, cholesterol), liver (glycogen, triglycerides and cholesterol) and muscle (glycogen and cholesterol) were also unaltered in rats receiving genistein. However, genistein administered at a higher dose evoked a significant reduction $(\mathrm{P} \leq 0.01)$ of muscle triglyceride stores. Results obtained in the experiment indicate that genistein may affect insulin and leptin-hormones responsible for metabolism, energy expenditure and food intake in young, sexually immature female rats. The muscle triglicerydes are the only metabolic parameter affected by the compound in these rats.
\end{abstract}

KEY WORDS: genistein, insulin, leptin, metabolism, rat

\footnotetext{
${ }^{*}$ This work is a part of E. Nowicka's PhD. Thesis

${ }^{1}$ Corresponding author: e-mail: tszkudel@jay.au.poznan.pl
} 


\section{INTRODUCTION}

Genistein is a plant-derived, isoflavone compound which belongs to the group called phytoestrogens. It is present predominantly in leguminous plants, but also in other vegetables, fruits and whole grains consumed by animals and humans. However, soya is the richest source of this phytoestrogen and contains milligrams of genistein per gram of dry matter (Price and Fenwick, 1985). Genistein may exist in plants as a bioactive aglycone - genistein or - more frequently - as an inactive glycoside - genistin (Price and Fenwick, 1985).

After consumption the glycoside form is hydrolysed by gut bacterial $\beta$-glucosidases or hydrochloric acid (Kelly et al., 1993). After absorption in the small intestine genistein is conjugated with glucuronic acid and sulphate by hepatic phase II enzymes. These conjugates are excreted by urine and bile, undergo enterohepatic circulation and can be deconjugated once again by gut bacteria and reabsorbed (Xu et al., 1995).

The action of genistein in the organism is pleiotropic and may include oestrogenic (e.g., reproductive functions; Dusza et al., 2006; Górski et al., 2006) - and antioestrogenic effects (e.g., some anticancerogenic effects; Kurzer and $\mathrm{Xu}, 1997)$. Genistein is a well known antioxidant compound. It also prevents cardiovascular disease and some postmenopausal problems e.g., osteoporosis. Soya protein or isoflavones added to the rat diet exert hypotriglyceridaemic action (Demonty et al., 2002). A similar effect may be demonstrated for pure genistein (Nogowski et al., 1998). Changes in metabolic parameters evoked by pure isoflavone administered to rats also involves an increase in blood free fatty acid contents and a decrease in liver glycogen stores (Nogowski et al., 2002).

In experiments in vitro genistein was found to augment free fatty acid output from the liver and abated the conversion of glucose into lipids (Nogowski et al., 1998). It was also demonstrated that the phytoestrogen substantially affected the metabolism of isolated rat adipocytes (Szkudelska et al., 2000).

Soya containing diets are commonly used in rodent feeding (Górski et al., 2006). Therefore, rodents may be influenced by isoflavones during different life stages. It may result in hormonal and metabolic disturbances. The effects concerning the metabolic action of genistein in vivo and in vitro come from studies performed on adult rats. In the majority of these experiments, intact males or ovariectomized animals were used. Recently, the effects of genistein in pregnant rats were also described (Nogowski et al., 2006). However, there is no literature data concerning the metabolic action of the isoflavone in very young rats. The purpose of the experiment was to determine the influence of genistein administered to sexually immature, female rats for a period of one week on some hormones and metabolic parameters. 


\section{MATERIAL AND METHODS}

\section{Animals and treatment}

Thirty four days old female, immature Wistar rats weighing $48 \pm 4 \mathrm{~g}$ were used. The experiment was performed according to rules accepted by Local Ethical Commission for Investigation on Animals. Rats were kept in cages in an air conditioned animal room in standard conditions - at constant temperature $\left(21 \pm 1^{\circ} \mathrm{C}\right)$ with a 12-h dark-light cycle and were fed ad libitum a soya-free diet (Motycz, Poland) containing no genistein. The fodder ingredients were: maize meal, wheat meal, oat meal, linseed oilmeal, yeast, egg powder, lactoalbumin, sugar beet pulp, vitamins and minerals. The energy value was $15.1 \mathrm{MJ}$ metabolizable energy $/ \mathrm{kg}$. Animals were divided into three groups (in each group $n=9$ ). Rats in the first (control) group received vehicle i.e. dimethyl sulphoxide: water mixture $(4: 6 \mathrm{v} / \mathrm{v}$; $0.5 \mathrm{ml} / 100 \mathrm{~g} \mathrm{BW}$ ) whereas rats in the second and third groups received vehicle with genistein (Sigma) at the amount 1 or $5 \mathrm{mg} / \mathrm{kg} \mathrm{BW}$, respectively. The vehicle or genistein solutions were administered intragastrically i.e. by using a cannula inserted via oesophagus into the stomach once a day for seven days. After this time, animals were killed by decapitation and their blood serum, liver and muscle were sampled and stored $\left(-80^{\circ} \mathrm{C}\right)$ until analysis.

\section{Determinations of hormone levels}

Serum concentration of insulin, leptin, thyrotropin and thyroid hormones (total and free thyroxine and triiodothyronine) were determined radioimmunologically by using kits from Linco Research Inc. (USA; for rat insulin and leptin), DRG Instruments $\mathrm{GmbH}$ (Germany; thyrotropin) and CIS Bio International (France; thyroid hormones).

\section{Determinations of metabolic parameters}

Glucose was assayed enzymatically with the use of glucose oxidase and o-dianisidine. The serum free fatty acid and triglyceride concentrations were determined by the method of Duncombe (1969) and Foster and Dunn (1973), respectively. The serum cholesterol (total, free and esterified) was estimaited by the enzymatic method described by Richmond (1973). High density lipoprotein (HDL) cholesterol was assayed as total cholesterol in the whole serum after separation of this lipoprotein fraction using polyethylene glycol. Liver and muscle glycogen was extracted and hydrolysed by amyloglucosidase (Szkudelska et al., 2003). After hydrolysis glucose was determined as described above. Liver and muscle triglyceride and cholesterol contents were determined as in serum after extraction of total lipids. 
To determine cholesterol content, the extract was evaporated and the parameter was assayed enzymatically (Richmond, 1973). The reagents used to determine metabolic parameters were obtained from Sigma (St. Louis, USA).

\section{Statistical analysis}

Differences between each group of rats were evaluated statistically using oneway analysis of variance and Duncan's multiple range test. Differences were considered significant at $\mathrm{P} \leq 0.05$ and $\mathrm{P} \leq 0.01$.

\section{RESULTS}

The effects of genistein on body weight gains and hormone levels

None of doses of genistein ( 1 or $5 \mathrm{mg}$ genistein $/ \mathrm{kg}$ body weight) administered for seven days influenced body weight gains (Table 1). It was, however,

Table 1. The effect of genistein on body weight gains and some hormones in the immature, female rats

\begin{tabular}{lccc}
\hline Parameter & Control & $\begin{array}{c}\text { Genistein } \\
1 \mathrm{mg} / \mathrm{kg}\end{array}$ & $\begin{array}{c}\text { Genistein } \\
5 \mathrm{mg} / \mathrm{kg}\end{array}$ \\
\hline Body weight gains, g/day & $4.22 \pm 0.25$ & $4.77 \pm 0.12$ & $4.18 \pm 0.29$ \\
Insulin, ng/ml & $1.59 \pm 0.11^{\mathrm{A}}$ & $1.35 \pm 0.15$ & $1.27 \pm 0.10^{\mathrm{B}}$ \\
Leptin, ng/ml & $0.99 \pm 0.08^{\mathrm{A}}$ & $0.95 \pm 0.09^{\mathrm{A}}$ & $0.70 \pm 0.11^{\mathrm{B}}$ \\
& & & \\
Triiodothyronine & & & \\
$\quad$ total, ng/ml & $0.87 \pm 0.04$ & $0.90 \pm 0.04$ & $0.79 \pm 0.05$ \\
$\quad$ free, pg/ml & $4.88 \pm 0.20$ & $4.77 \pm 0.16$ & $4.35 \pm 0.21$ \\
Thyroxine & & & \\
$\quad$ total, ng/ml & & & \\
$\quad$ free, pg/ml & $35.69 \pm 1.93$ & $39.42 \pm 2.78$ & $34.11 \pm 1.86$ \\
Thyrotropin, ng/ml & $21.31 \pm 1.58$ & $22.91 \pm 1.52$ & $19.70 \pm 1.75$ \\
\hline genistein was dissolved in dimethyl sulphoxide & & \\
\end{tabular}

genistein was dissolved in dimethyl sulphoxide: water mixture $(4: 6 \mathrm{v} / \mathrm{v} ; 0.5 \mathrm{~mL} / 100 \mathrm{~g}$ body weight) and was administered intragastrically once a day for 7 days. Rats in control group received only vehicle. Values are means \pm SEM for 9 animals. Means in the same row with different letter superscripts differ significantly $(\mathrm{P} \leq 0.01)$

observed that genistein administered at the dose $5 \mathrm{mg} / \mathrm{kg} \mathrm{BW}$ affected the hormonal status of the organism. Blood insulin concentration was significantly $(\mathrm{P} \leq 0.01)$ diminished in these rats in comparison to animals receiving the vehicle (Table 1). In rats treated with genistein at the lower dose, blood insulin level tended to be reduced, but the difference was not statistically significant. In the group of animals 
receiving the higher dose of genistein, blood leptin level was diminished $(\mathrm{P} \leq 0.01$; Table 1). The concentration of blood thyrotropin (TSH) tended to be lowered by $5 \mathrm{mg} / \mathrm{kg}$ genistein, but the effect was not statistically significant. Total and free thyroxine $\left(\mathrm{T}_{4}\right)$ and triiodothyronine $\left(\mathrm{T}_{3}\right)$ in blood serum of genistein-treated rats were unaffected (Table 1).

\section{The effects of genistein on metabolic parameters}

Blood glucose, triglyceride and free fatty acid concentrations were not affected by genistein at any dose. It was also demonstrated that the phytoestrogen had no influence on total, free and esterified cholesterol in blood and on total cholesterol in high density lipoproteins (Table 2). Liver glycogen, triglycerides and cholesterol were also unaffected in rats receiving genistein. In these animals, genistein had no effect on muscle glycogen and cholesterol. However, muscle triglyceride content was substantially $(\mathrm{P} \leq 0.01)$ lowered by genistein administered at the dose $5 \mathrm{mg} / \mathrm{kg} \mathrm{BW}$ (Table 2). This effect was not observed in rats receiving the tested phytoestrogen at the lower dose.

Table 2. The effect of genistein on metabolic parameters in the immature, female rats

\begin{tabular}{|c|c|c|c|}
\hline Parameter & Control & $\begin{array}{l}\text { Genistein } \\
1 \mathrm{mg} / \mathrm{kg}\end{array}$ & $\begin{array}{l}\text { Genistein } \\
5 \mathrm{mg} / \mathrm{kg}\end{array}$ \\
\hline \multicolumn{4}{|l|}{ Blood serum } \\
\hline glucose, $\mathrm{mmol} / \mathrm{l}$ & $4.52 \pm 0.17$ & $4.44 \pm 0.14$ & $4.42 \pm 0.14$ \\
\hline triglycerides, mmol/1 & $2.74 \pm 0.15$ & $2.63 \pm 0.12$ & $2.49 \pm 0.12$ \\
\hline $\begin{array}{l}\text { free fatty acids, } \mathrm{mmol} / \mathrm{l} \\
\text { cholesterol, } \mathrm{mmol} / \mathrm{l}\end{array}$ & $0.18 \pm 0.02$ & $0.16 \pm 0.01$ & $0.22 \pm 0.02$ \\
\hline total & $1.28 \pm 0.05$ & $1.48 \pm 0.09$ & $1.34 \pm 0.07$ \\
\hline esterified & $0.78 \pm 0.03$ & $0.91 \pm 0.04$ & $0.90 \pm 0.04$ \\
\hline free & $0.50 \pm 0.03$ & $0.57 \pm 0.04$ & $0.44 \pm 0.04$ \\
\hline HDL cholesterol, mmol/1 & $0.47 \pm 0.02$ & $0.56 \pm 0.03$ & $0.52 \pm 0.03$ \\
\hline Cholesterol HDL/total, mmol/1 & $0.37 \pm 0.02$ & $0.37 \pm 0.02$ & $0.39 \pm 0.01$ \\
\hline \multicolumn{4}{|l|}{ Liver } \\
\hline glycogen, $\mathrm{g} / \mathrm{kg}$ & $36.78 \pm 2.25$ & $36.49 \pm 3.71$ & $32.90 \pm 5.76$ \\
\hline triglycerides, $\mathrm{mmol} / \mathrm{kg}$ & $8.37 \pm 0.77$ & $8.76 \pm 0.42$ & $8.09 \pm 0.63$ \\
\hline cholesterol, mmol/kg & $5.67 \pm 0.14$ & $5.63 \pm 0.21$ & $5.81 \pm 0.22$ \\
\hline \multicolumn{4}{|l|}{ Muscle } \\
\hline glycogen, $\mathrm{g} / \mathrm{kg}$ & $0.36 \pm 0.03$ & $0.30 \pm 0.05$ & $0.34 \pm 0.05$ \\
\hline triglycerides, $\mathrm{mmol} / \mathrm{kg}$ & $16.03 \pm 3.10^{\mathrm{A}}$ & $14.41 \pm 2.23^{\mathrm{A}}$ & $7.18 \pm 1.64^{\mathrm{B}}$ \\
\hline cholesterol, $\mathrm{mmol} / \mathrm{kg}$ & $2.26 \pm 0.201$ & $2.26 \pm 0.21$ & $1.83 \pm 0.25$ \\
\hline
\end{tabular}

genistein was dissolved in dimethyl sulphoxide: water mixture $(4: 6 \mathrm{v} / \mathrm{v} ; 0.5 \mathrm{~mL} / 100 \mathrm{~g}$ body weight) and was administered intragastrically once a day for 7 days. Rats in control group received only vehicle. Values are means \pm SEM for 9 animals. Means in the same row with different letter superscripts differ significantly $(\mathrm{P} \leq 0.01)$ 


\section{DISCUSSION}

In the performed experiment it was demonstrated that genistein at the dose $5 \mathrm{mg} / \mathrm{kg}$ body weight administered for seven days significantly decreased blood insulin concentration in the immature female rats. Similar effect was observed for the first time in the older, weighing about $200 \mathrm{~g}$, male rats receiving the phytoestrogen at the same dose, but only for three days (Szkudelska et al., 2003). These results imply that the influence of genistein on insulin concentration is sexindependent and may occur in both very young and older rats. Ascencio et al. (2004) found that in rats consuming soya protein (containing also phytoestrogens) blood insulin was significantly lowered in comparison with animals fed caseinsupplemented diet. Results of our previous (Szkudelska et al., 2003) and recent (Table 1) studies indicate that genistein may be, at least in part, responsible for this hipoinsulinaemic effect of soya protein. The reason of the reduced blood insulin content induced by genistein is not clear. It is well known that the main physiological stimulator of insulin secretion is glucose. However, in rats receiving genistein the decrease in blood insulin was not accompanied by any changes in blood glucose concentrations. This observation appears to indicate a direct inhibitory influence of the tested compound on insulin secretion. On the other hand, experiments performed on pancreatic islets isolated from 3-5 day old (Sorenson et al., 1994) or adult (Liu et al., 2006) rats indicate that in vitro genistein potentiates glucoseinduced insulin secretion.

Some studies have reported that soya protein exerts numerous beneficial effects in relation to blood lipids in diabetic animals and humans (Ae Park et al., 2006). However, pure genistein acting at the post-receptor level was found to restrict some effects of insulin in the cell (Abler et al., 1992). Moreover, in experiments with perfused liver, genistein added to the medium diminished binding capacity of insulin receptors (Maćkowiak et al., 1999). A similar effect was observed in the liver of ovariectomized rats receiving the phytoestrogen for three days (Nogowski et al., 2002). These results, together with our observations demonstrating that genistein decreases blood insulin concentration (Table 1; Szkudelska et al., 2003), indicate that this phytoestrogen is rather a factor exerting the anti-insulinic action.

Apart from insulin, leptin is another pivotal hormone participating in the regulation of food intake and in the control of the energetic status of the organism. The main source of circulating leptin are cells of white adipose tissue. The blood leptin content may be affected, among others, by some food-derived factors. In our experiment genistein $(5 \mathrm{mg} / \mathrm{kg} \mathrm{BW})$, administered to rats for seven days substantially diminished blood leptin concentrations. One of the reasons of this effect could be the concomitant decrease in blood insulin found in these animals. The pancreatic hormone stimulates glucose transport and metabolism providing ATP in adipocytes and thereby potentiates the secretion of leptin (Mueller et al., 1998). Besides, insulin itself is able to enhance leptin secretion from fat cells (reviewed by Szkudelski, 
2007). However, in our experiment, the difference in blood insulin concentrations between rats receiving genistein at low and high dose was negligible, whereas leptin levels were diminished solely in animals receiving phytoestrogen at higher dose. The latter effect may be the consequence of direct genistein action on fat cells. Numerous effects of genistein in rat adipocytes which may contribute to the inhibition of leptin secretion are well documented. It was demonstrated that genistein, acting at the postreceptor level, attenuates insulin action in fat cells (Abler et al., 1992). Moreover, the phytoestrogen was found to restrict the insulin-stimulated glucose transport in adipocytes due to conformational changes of GLUT4 (Smith et al., 1993). Abler et al. (1992) observed that genistein abated insulin-stimulated metabolism of glucose in fat cells. It was also shown that the isoflavone restricts glucose and acetate conversion to lipids in isolated rat adipocytes (Nogowski et al., 1998; Szkudelska et al., 2000). The inhibition of glucose transport and/or metabolism depletes ATP content in adipocytes resulting in restricted secretion of leptin (Mueller et al., 1998). Furthermore, results of our recent experiments provided an evidence that genistein is able to substantially attenuate secretion of leptin from isolated rat adipocytes (Szkudelski et al., 2005). Therefore, it is possible that the isoflavone exerts a similar effect in vivo via its direct action on fat cells and that this action results in reduced blood leptin level. It is noteworthy, that the diminution of blood leptin concentrations in genistein-treated rats had no effect on body weight gains in these animals.

Chang and Doerge (2000) demonstrated that in rats consuming genisteinenriched diet for 20 weeks, the phytoestrogen was present in thyroid tissue and evoked a substantial reduction in thyroid peroxidase activity. This effect was, however, not accompanied by changes in blood thyrotropin, as well as total $\mathrm{T}_{3}$ and $\mathrm{T}_{4}$ levels. In our experiment, apart from thyrotropin and total thyroid hormone concentrations, free $\mathrm{T}_{3}$ and $\mathrm{T}_{4}$ in the blood were also analysed. However, genistein administered for 7 days did not disturb euthyreosis, as evidenced by the lack of changes in total and free thyroid hormone and thyrotropin levels.

In skeletal muscles of the immature female rats receiving genistein at the higher dose, a substantial reduction of triglyceride stores was observed. Such an effect was also found in the mature male rats treated with the phytoestrogen for three days (Szkudelska et al., 2003) and in female rats (Nogowski et al., 1998, 2002). However, the latter animals were ovariectomized, i.e. deprived of natural oestrogens. It is noteworthy that oestradiol administered to male rats at the dose 50 times lower than genistein also diminished muscle triglycerides (Szkudelska et al., 2003). These results indicate that genistein and oestradiol may exert similar influence on muscle triglyceride contents. In the case of the ovarian hormone, this effect seems to by partially due to decreased activity of muscle lipoprotein lipase (Ramirez, 1981). Genistein-induced diminution in muscle triglyceride stores may be related to the oestrogenic activity of the isoflavone; however, the mechanism underlying this action remains unknown. 
Unlike muscle triglycerides, in this experiment and in our previous studies (Nogowski et al., 2002; Szkudelska et al., 2003) genistein did not affect liver triglyceride contents. Many other parameters of carbohydrate and lipid metabolism analysed in this experiment were also unaffected by the tested compound.

In conclusion, results obtained in our experiment revealed that genistein may substantially reduce blood insulin and leptin levels and diminish muscle triglyceride reserves in young, sexually immature female rats. These effects were observed after seven days of genistein administration but only in rats receiving the compound at higher dose.

\section{REFERENCES}

Abler A., Smith J.A., Randazzo P.A., Rothenberg P.L., Jarett L., 1992. Genistein differentially inhibits postreceptor effects of insulin in rat adipocytes without inhibiting the receptor kinase. J. Biol. Chem. 267, 3946-3951

Ae Park S., Choi M.S., Cho S.Y., Seo J.S., Jung U.J., Kim M.J., Sung M.K., Park Y.B., Lee M.K., 2006. Genistein and daidzein modulate hepatic glucose and lipid regulating enzyme activities in C57BL/KsJ-db/db mice. Life Sci. 79, 1207-1213

Ascencio C., Torres N., Isoard-Acosta F., Gomez-Perez F.J., Hernandez-Pando R., Tovar A.R., 2004. Soy protein affects serum insulin and hepatic SREBP-1 mRNA and reduces fatty liver in rats. J. Nutr. 134, 522-529

Chang H.C., Doerge D.R., 2000. Dietary genistein inactivates rat thyroid peroxidase in vivo without an apparent hypothyroid effect. Toxicol. Appl. Pharmacol. 168, 244-252

Demonty I., Lamarche B., Deshaies Y., Jacques H., 2002. Role of soy isoflavones in the hypotriglyceridemic of soy protein in the rat. J. Nutr. Biochem. 13, 671-677

Duncombe D., 1969. The colorimetric micro-determination of nonesteryfied fatty acids in plasma. Clin. Chim. Acta 9, 122-125

Dusza L., Ciereszko R.E., Skarżyński D.J., Nogowski L., Opałka M., Kamińska B., Nynca A., Kraszewska O., Słomczyńska M., Wocławek-Potocka I., Korzekwa A., Pruszyńska-Oszmałek E., Szkudelska K., 2006. Mechanism of phytoestrogens action in reproductive processes of mammals and birds. Reprod. Biol. 6, Suppl. 1, 151-174

Foster L.B., Dunn R.T., 1973. Stable reagents for determination of serum triglicerides by colorimetric Hatzsh condensation method. Clin. Chem. 19, 338-340

Górski K., Taciak M., Romanowicz K., Misztal T., 2006. Differential effects of soy-containing diets on the reproductive tissues growth and reproductive hormone secretion in male rats. Reprod. Biol. 6, 275-289

Kelly G.E., Nelson C., Waring M.A., Joannou G.E., Reeder A.Y., 1993. Metabolites of dietary (soya) isoflavones in human urine. Clin. Chim. Acta 223, 9-22

Kurzer M.S., Xu X., 1997. Dietary phytoestrogens. Annu. Rev. Nutr. 17, 353-381

Liu D., Zhen W., Yang Z., Carter J.D., Si H., Reynolds K.A., 2006. Genistein acutely stimulates insulin secretion in pancreatic beta-cells through a cAMP-dependent protein kinase pathway. Diabetes 55, 1043-1050

Maćkowiak P., Nogowski L., Nowak K.W., 1999. Effect of isoflavone genistein on insulin receptors in perfused liver of ovariectomized rats. J. Recept. Signal. Transduct. Res. 19, 283-292 
Mueller W.M., Gregoire F.M., Stanhope K.L., Mobbs C.V., Mizuna T.M., Warden C.H., Stern J.S., Havel P.J., 1998. Evidence that glucose metabolism regulates leptin secretion from cultured rat adipocytes. Endocrinology 139, 551-558

Nogowski L., Maćkowiak P., Kandulska K., Szkudelski T., Nowak K.W., 1998. Genistein-induced changes in lipid metabolism of ovariectomized rats. Ann. Nutr. Metab. 42, 360-366

Nogowski L., Nowak K.W., Kaczmarek P., Maćkowiak P., 2002. The influence of coumestrol, zearalenone, and genistein administration on insulin receptors and insulin secretion in ovariectomized rats. J. Recept. Signal. Transduct. Res. 22, 449-457

Nogowski L., Szkudelska K., Szkudelski T., Pruszyńska-Oszmałek E., 2006. The effect of phytoestrogen, genistein, on the hormonal and metabolic status of pregnant rats. J. Anim. Feed Sci. 15, 275-286

Price K.R., Fenwick G.R., 1985. Naturally occurring oestrogens in foods - a review. Food Addit. Contam. 2, 73-106

Ramirez I., 1981. Estradiol-induced changes in lipoprotein lipase, eating, and body weight in rats. Amer. J. Physiol. 240, 533-538

Richmond W., 1973. Preparation and properties of cholesterol oxidase from Nocardia sp. and application to the enzymatic assay of total cholesterol in serum. Clin. Chem. 19, 1350-1356

Smith R.M., Tiesinga J.J., Shah N., Smith J.A., Jarett L., 1993. Genistein inhibits insulin-stimulated glucose transport and decreases immunocytochemical labeling of GLUT4 carboxyl-terminus without affecting translocation of GLUT4 in isolated rat adipocytes: additional evidence of GLUT4 activation by insulin. Arch. Biochem. Biophys. 300, 238-246

Sorenson R.L., Brelje T.C., Roth C., 1994. Effect of tyrosine kinase inhibitors on islets of Langerhans: evidence for tyrosine kinases in the regulation of insulin secretion. Endocrinology 134, 19751978

Szkudelska K., Nogowski L., Kaczmarek P., Pruszyńska-Oszmałek E., Szkudelski R., Sieczka A., Szkudelski T., 2003. Hormonal and metabolic effects of genistein and daidzein in male rats. J. Anim. Feed Sci. 12, 839-847

Szkudelska K., Nogowski L., Szkudelski T., 2000. Genistein affects lipogenesis and lipolysis in isolated rat adipocytes. J. Steroid Biochem. Mol. Biol. 75, 265-271

Szkudelski T., 2007. Intracellular mediators in regulation of leptin secretion from adipocytes. Physiol. Res. (in press)

Szkudelski T., Nogowski L., Pruszyńska-Oszmałek E., Karczmarek P., Szkudelska K., 2005. Genistein restricts leptin secretion from rat adipocytes. J. Steroid Biochem. Mol. Biol. 96, 301307

Xu X., Harris K.S., Wang H.J., Murphy P.A., Hendrich S., 1995. Bioavailability of soybean isoflavones depends upon gut microflora in women. J. Nutr. 124, 825-832 